\title{
Bronchoscopic Lung Volume Reduction with Endobronchial Valves in Low-FEV 1 Patients
}

\author{
Kaid Darwiche ${ }^{a}$ Rüdiger Karpf-Wissel ${ }^{a} \quad$ Stephan Eisenmann ${ }^{a}$ Clemens Aigner $^{b}$ \\ Stefan Welter ${ }^{b}$ Paul Zarogoulidis ${ }^{d}$ Wolfgang Hohenforst-Schmidt ${ }^{c}$ \\ Lutz Freitag $^{\mathrm{e}}$ Filiz Oezkan ${ }^{\mathrm{a}}$ \\ Departments of a Interventional Pneumology and ${ }^{b}$ Thoracic Surgery, Ruhrlandklinik, University Hospital Essen, \\ University of Duisburg-Essen, Essen, and 'Medical Clinic I, "Fuerth" Hospital, University of Erlangen, Fuerth,

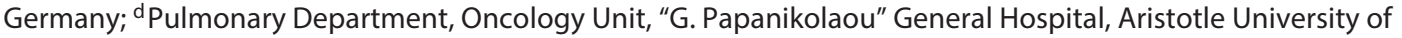 \\ Thessaloniki, Thessaloniki, Greece; ${ }^{e}$ Department of Pulmonology, University Hospital Zurich, Zurich, Switzerland
}

\section{For editorial comment see p. 359}

\section{Keywords}

Endoscopic lung volume reduction · Lung volume reduction surgery · Interventional bronchoscopy · Lung emphysema - Chronic obstructive pulmonary disease · Bronchoscopy

\begin{abstract}
Background: Bronchoscopic lung volume reduction (BLVR) with valves has been shown to improve lung function, exercise capacity, and quality of life in patients with emphysema, but only few patients with forced expiratory volume in $1 \mathrm{~s}$ $\left(\mathrm{FEV}_{1}\right) \leq 20 \%$ predicted have been included in former studies. Although the procedure can be performed safely, pneumothorax is a frequent complication, which can be critical for these very severely diseased patients. Objectives: The aim of the study was to assess the safety of BLVR in patients with a very advanced stage of emphysema, as indicated by $\mathrm{FEV}_{1} \leq 20 \%$ predicted. Patients and Methods: Patients in whom BLVR was performed between January 2013 and August 2015 were included in this analysis if their baseline predicted $\mathrm{FEV}_{1}$ was $\leq 20 \%$. BLVR, performed only if collateral ventilation was absent, achieved complete occlusion of the
\end{abstract}

\section{KARGER} www.karger.com/res
E-Mail karger@karger.com target lobe. All patients were closely monitored and were Twenty patients with $\mathrm{FEV}_{1} \leq 20 \%$ predicted were included in the analysis. Lung volume reduction was achieved in $65 \%$ of the cases. Pneumothorax occurred in 4 cases (20\%). No patient died. Lung function and exercise tolerance improved after 1 and 3 months, respectively. Conclusions: BLVR with valves can be safely performed in patients with $\mathrm{FEV}_{1} \leq 20 \%$ predicted when close postprocedural monitoring is provided. Improvement in lung function and exercise capacity can be achieved.

(c) 2016 S. Karger AG, Basel

\section{Introduction}

Surgical lung volume reduction has been shown to improve lung function, exercise capacity, and quality of life in lung emphysema patients [1]. Bronchoscopic lung volume reduction (BLVR) by placement of endobronchial valves is a more recent, less invasive development to induce atelectasis of the most damaged lobe. In selected patients with heterogeneously distributed emphysema, not discharged before the fourth day after BLVR. Results:
C 2016 S. Karger AG, Basel

0025-7931/16/0926-0414\$39.50/0 
BLVR can achieve a significant increase in lung function, exercise capacity, and quality of life and a decrease in hyperinflation and dyspnea on exertion $[2,3]$. As a prerequisite, interlobar collateral ventilation of the target lobe must be excluded, for instance, by a Chartis physiological collateral ventilation measurement [4].

In the NETT trial of surgical lung volume reduction, the mortality of patients with very advanced destruction of the lung, resulting in forced expiratory volume in $1 \mathrm{~s}$ $\left(\mathrm{FEV}_{1}\right) \leq 20 \%$ predicted, was significantly higher than in subjects with higher $\mathrm{FEV}_{1}$ [1]. Only few "low-FEV " patients were included in subsequent trials for surgical or bronchoscopic LVR. Patients with severe emphysema suffer from significantly impaired gas exchange and diminished ventilatory capacity. Comorbidities are also frequent in these patients, resulting in an increased risk of periinterventional complications for any form of invasive treatment [5]. It is, therefore, unknown whether BLVR with valves can be performed safely in low-FEV ${ }_{1}$ patients, and the aim of this study was to examine this aspect.

\section{Materials and Methods}

\section{Patients}

This retrospective analysis included patients who underwent BLVR treatment with endobronchial valves in our tertiary care center between January 2013 and August 2015 if their baseline $\mathrm{FEV}_{1}$ was $\leq 20 \%$ predicted. The ethics committee of the University of Essen approved the study protocol. All patients with severe hyperinflation and advanced emphysema had been treated with endobronchial valves (Zephyr ${ }^{\complement}$ Endobronchial Valve; Pulmonx, Inc., Redwood City, CA, USA). For each patient, heterogeneity of the emphysema was visually assessed by high-resolution computed tomography (HRCT) and perfusion scan in a multidisciplinary conference that included, in addition to general and interventional pulmonologists, a lung transplant physician and a thoracic surgeon experienced in lung volume reduction surgery. In this conference, the general suitability for BLVR treatment was discussed, and only patients with heterogeneously distributed emphysema were selected for BLVR. Patients with no or hardly any perfusion in the target lobe were classified as very heterogeneous. As volumetric HRCT scans were not available in our institution before September 2015 , volumetric emphysema quantification data could not be assessed. All patients underwent a pulmonary rehabilitation program and had stopped smoking for at least 6 months prior to BLVR indication. Patients who had been listed for lung transplantation were also evaluated for BLVR, which was then used to bridge the time to lung transplantation. Echocardiography was performed to exclude significant cardiac insufficiency. Significant hypoxemia or hypercapnia was treated by oxygen supply or noninvasive ventilation. Patients with a history of any thoracic surgery or lung volume reduction, with sputum excess or more than 2 exacerbations per year, were excluded from BLVR treatment
Valve Placement

In all patients undergoing a BLVR procedure, a laryngeal mask or a rigid bronchoscope was placed under deep sedation that allowed spontaneous breathing. The target lobe was determined from the HRCT scan and perfusion scans. A Chartis measurement was performed at the beginning of the procedure to assess and exclude the presence of interlobar collateral ventilation of the target lobe [6]. Patients with collateral ventilation were deemed inadequate for valve placement. When the endoscopist was uncertain about the most appropriate target lobe (e.g., when there was similarly reduced perfusion in more than 1 target lobe), a lobar endobronchial gas exchange measurement was performed using a dedicated in-house developed equipment (Super-Chartis) as described by Freitag et al. [7]. In this case, the lobe with poorest gas exchange was selected for treatment. After these 2 measurements, endobronchial valves $\left(\right.$ Zephyr $\left.^{\odot}\right)$ were placed to achieve complete occlusion of the target lobe. According to our standard protocol, all patients were monitored for $24 \mathrm{~h}$ in the intensive care unit (ICU) and were not discharged from hospital before the fourth day after BLVR. Chest radiography was performed after $2 \mathrm{~h}$ and on the next morning to exclude pneumothorax and to examine the occurrence of target lobe atelectasis. Patients were informed about the possibility of a late pneumothorax after discharge.

\section{Follow-Up}

Efficacy follow-ups were performed at 30 days and at 90 days after BLVR. Pulmonary function tests, 6-minute walk test, and chest radiography were repeated at each follow-up. A CT scan was occasionally performed at follow-up.

For safety analysis, all complications were recorded during the whole course of patient follow-up. Target lobe atelectasis was assessed by X-ray and classified as "full atelectasis" when it could be observed on X-ray, as "sign of atelectasis" when a rise of the diaphragm or an ipsilateral mediastinal shift was present, and as "no atelectasis" when none of the above signs were present. Two radiologists interpreted each chest radiograph together.

\section{Statistical Analysis}

The Student $t$ test for paired samples was used to examine mean differences in changes from baseline to follow-up values. Intention-to-treat analyses were performed on all end points. An increase of $>10 \%$ in $\mathrm{FEV}_{1}$ [8] and of $>26 \mathrm{~m}$ in the 6-minute walk test [9] as well as a reduction of $\geq 430 \mathrm{~mL}$ in residual volume [10] were considered requirements for a minimal clinically important difference. A $p$ value of $<0.05$ was considered statistically significant.

\section{Results}

\section{Baseline Characteristics and Procedural Results}

Twenty consecutive patients referred to our bronchoscopy unit between January 2013 and August 2015 with very severe emphysema and treated with $Z_{\text {ephyr }}{ }^{\odot}$ valves for BLVR fulfilled the inclusion criteria and were included in our analysis. Baseline data are presented in detail in Table 1. Three out of 20 patients (15\%) had homozygote a1-antitrypsin deficiency. At baseline, 18/20 patients 
(90\%) needed supplemental oxygen and 2/20 patients (10\%) required noninvasive ventilation. Coronary heart disease, osteoporosis, and arterial hypertension were present in 7, 6, and 2 subjects, respectively. Mild pulmonary hypertension, assessed by echocardiography, was present in 12 out of 20 patients $(60 \%)$ with a systolic pulmonary artery pressure ranging from 26 to $39 \mathrm{~mm} \mathrm{Hg}$. The systolic pulmonary artery pressure of the remaining 8 patients was $\leq 25 \mathrm{~mm} \mathrm{Hg}$. Two patients were listed for lung transplantation. Ten patients (50\%) presented with very heterogeneously distributed emphysema according to HRCT and perfusion scan read by experienced physicians and discussed during the multidisciplinary conference. Chartis measurement was performed in all patients. In 3 patients, a low-flow pattern was revealed, and collateral ventilation could be excluded in the rest of the patients.

The treated lobes can be seen in Table 2. Complete lobar occlusion was achieved using 1-8 valves (median 3 ) per patient.

\section{Safety}

All patients were followed for at least 90 days for adverse events. Complications recorded are listed in Table 3. Four patients (20\%) developed a pneumothorax, all of which occurred within $24 \mathrm{~h}$ after BLVR, 1 with tension pneumothorax and rapid deterioration. A chest tube was immediately placed to prevent respiratory failure. In 2 patients, chest tube placement and suction alone successfully treated the air leaks. In the other 2 patients, valve removal and thoracoscopy were needed to treat persistent air leaks. One patient requested and underwent valve removal after 3 months due to lack of respiratory improvement. These 3 patients were included in the efficacy anal$y$ sis and in the safety analysis. A mild COPD exacerbation and pneumonia in a nontreated lobe occurred in 2 patients. In 1 patient, a loss of atelectasis was resolved following an bronchoscopic review and a position change for 1 of the valves. Data for the 3-month follow-up were taken after this revision date. Respiratory failure requiring mechanical ventilation was not observed in any patient. No patient died within the mean observation time of $21 \pm 8$ months (range 9-33).

\section{Outcome Measurements}

Radiography

Thirty days after valve implantation, evidence of successful lung volume reduction was observed on chest radiography after BLVR in 13 cases (65\%). In 7 of these patients (35\%), chest radiography revealed a complete atelectasis of the treated lobe, while in the other 6 patients, signs of atel-
Table 1. Baseline characteristics of low- $-\mathrm{FEV}_{1}$ patients who underwent bronchoscopic lung volume reduction with valves
Patients, $n$

Gender, male/female

Age, years

Homozygote a1-antitrypsin deficiency

Very heterogeneous emphysema

BMI

$\mathrm{FEV}_{1}, \mathrm{~L}$

$\mathrm{FEV}_{1} \%$

$\mathrm{RV}, \mathrm{L}$

$\mathrm{RV} \%$

IVC, L

IVC $\%$

DLCO \%

6-MWD, m

Oxygen supplementation

Noninvasive ventilation

Mild pulmonary hypertension
20

$11 / 9$

$59.3 \pm 5.9$

$3 / 20(15)$

$10 / 20(50)$

$22.0 \pm 3.6$

$0.52 \pm 0.12$

$17.8 \pm 1.9$

$7.5 \pm 1.6$

$315 \pm 70$

$1.75 \pm 0.58$

$49.2 \pm 12.3$

$21.5 \pm 8.8$

$283 \pm 66$

$18 / 20(90)$

$2 / 20(10)$

$12 / 20(60)$
Values are means \pm standard deviations or numbers with percentages in parentheses. BMI, body mass index; $\mathrm{FEV}_{1}$, forced expiratory volume in $1 \mathrm{~s} ; \mathrm{RV}$, residual volume; IVC, inspiratory vital capacity; DLCO, diffusing capacity of the lung for carbon monoxide; 6-MWD, 6-minute walking distance.

Table 2. Target lobe and atelectasis assessment 30 days after BLVR

\begin{tabular}{lllll}
\hline & Patients & $\begin{array}{l}\text { Full TL } \\
\text { atelectasis }\end{array}$ & $\begin{array}{l}\text { Signs of TL } \\
\text { atelectasis }\end{array}$ & $\begin{array}{l}\text { No signs of } \\
\text { atelectasis }\end{array}$ \\
\hline RUL & 5 & 1 & 1 & 3 \\
RML & 1 & 0 & 1 & 0 \\
RLL & 3 & 0 & 1 & 2 \\
LUL & 6 & 3 & 2 & 1 \\
LLL & 5 & 3 & 1 & 1 \\
\hline Total & 20 & 7 & 6 & 7 \\
\hline
\end{tabular}

Values are numbers. BLVR, bronchoscopic lung volume reduction; TL, target lobe; RUL, right upper lobe; RML, right middle lobe; RLL, right lower lobe; LUL, left upper lobe; LLL, left lower lobe.

ectasis were detected by an upward rise of the hemidiaphragm and an ipsilateral mediastinal shift (Table 2). Lung volume reduction that had been achieved after 1 month persisted at the 3-month follow-up in all patients.

\section{Lung Function and Exercise Tolerance}

The pulmonary function test results and the 6-minute walk test results at baseline and at 30 and 90 days after
Darwiche et al. 
Table 3. Complications observed within 30 days after BLVR

\begin{tabular}{|c|c|c|}
\hline Events & $n$ & Treatments \\
\hline $\begin{array}{l}\text { Intraoperative/perioperative } \\
\text { pneumothorax }\end{array}$ & 4 & VATS (2), drainage (2) \\
\hline Late pneumothorax & 0 & - \\
\hline Pneumonia & 3 & antibiotics \\
\hline Exacerbations & 2 & antibiotics \\
\hline Respiratory insufficiency & 0 & - \\
\hline Loss of atelectasis & 1 & $\begin{array}{l}\text { valve removal + valve } \\
\text { reimplantation }\end{array}$ \\
\hline Respiratory insufficiency & 0 & - \\
\hline Death & 0 & - \\
\hline $\begin{array}{l}\text { Removal of valves (patient's } \\
\text { request) }\end{array}$ & 1 & listed for LuTx \\
\hline
\end{tabular}

BLVR, bronchoscopic lung volume reduction; VATS, videoassisted thoracoscopic surgery; LuTx, lung transplantation.
Table 5. Comparison of changes in lung function and exercise capacity 90 days after BLVR with valves between the atelectasis and the nonatelectasis group

\begin{tabular}{lccr}
\hline & $\begin{array}{l}\text { Atelectasis or } \\
\text { sign of atelectasis }\end{array}$ & $\begin{array}{l}\text { No sign of } \\
\text { atelectasis }\end{array}$ & $p$ value \\
\hline Patients, $n$ & 10 & 7 & \\
$\Delta \mathrm{FEV}_{1}, \mathrm{~L}$ & $+0.2 \pm 0.2$ & $-0.0 \pm 0.1$ & $<0.01$ \\
$\Delta \mathrm{RV}, \mathrm{L}$ & $-1.49 \pm 1.45$ & $-0.63 \pm 0.89$ & 0.18 \\
$\Delta$ 6-MWD, m & $+52.5 \pm 98.8$ & $+16.7 \pm 58.5$ & 0.41 \\
\hline
\end{tabular}

BLVR, bronchoscopic lung volume reduction; $\mathrm{FEV}_{1}$, forced expiratory volume in $1 \mathrm{~s}$; RV, residual volume; 6-MWD, 6-minute walking distance.

Table 4. Outcome (intention-to-treat-analysis): changes in lung function and exercise capacity 30 and 90 days after bronchoscopic lung volume reduction with valves

\begin{tabular}{|c|c|c|c|c|c|c|}
\hline$\Delta \mathrm{FEV}_{1} \%$ from baseline & -16.4 to +75 & $+25.2 \pm 29.6$ & & -11.7 to +110 & $+22.8 \pm 32.9$ & \\
\hline$\Delta \mathrm{RV}, \mathrm{L}$ & -4.1 to +1.1 & $-1.1 \pm 1.3$ & $<0.01$ & -4.2 to +1.6 & $-1.14 \pm 1.79$ & $<0.05$ \\
\hline$\Delta \mathrm{RV} \%$ from baseline & -52.6 to +16.9 & $-13.4 \pm 19.3$ & & -43.4 to +18.1 & $-12.5 \pm 23.3$ & \\
\hline$\Delta 6-\mathrm{MWD}, \mathrm{m}$ & -130 to +130 & $+10 \pm 68$ & n.s. & -80 to +205 & $+33.0 \pm 76.3$ & n.s. \\
\hline$\Delta 6$-MWD $\%$ from baseline & -61.9 to +60 & $+4.1 \pm 33.2$ & & -21.1 to +102.5 & $+18 \pm 34.6$ & \\
\hline
\end{tabular}

$p$ values in italics are statistically significant. $\mathrm{FEV}_{1}$, forced expiratory volume in $1 \mathrm{~s}$; RV, residual volume; IVC, inspiratory vital capacity; 6-MWD, 6-minute walking distance; n.s., not significant.

BLVR are shown in Table 4. $\mathrm{FEV}_{1}$ and residual volume improved significantly 30 days after BLVR and were maintained afterwards at 90 days. At 30 days $10 / 17$ patients (59\%) and at 90 days $8 / 17$ patients $(47 \%)$ reached the criteria for a minimal clinically important difference in $\mathrm{FEV}_{1}$ (i.e., > 10\%). And at 30 days 10/17 patients (59\%) and at 90 days $10 / 17$ patients (59\%) reached the criteria for a minimal clinically important difference in residual volume $(-430 \mathrm{~mL})$.

The 6-minute walking distance increased at 1 month and at 3 months. Six out of 17 patients (35\%) and 9/17 patients (53\%) improved meaningfully ( $>26 \mathrm{~m}$ ) after 30 and 90 days, respectively.
Impact of Atelectasis on Functional Outcome

Table 5 shows the impact of atelectasis on clinical outcome. At 90 days, 10/17 patients (58\%) displayed a full atelectasis or signs of atelectasis on chest X-ray. These patients showed a larger increase in $\mathrm{FEV}_{1}$ than those without atelectasis $(0.2 \pm 0.2$ vs. $0 \pm 0.1 \mathrm{~L}, p<0.01)$, while the 6-minute walk test did not reach a statistically significant difference between these 2 groups ( $52.5 \pm 98.9$ vs. $16.7 \pm 58.5 \mathrm{~m}, p=0.41)$. 


\section{Discussion}

In the present study, we analyzed the safety and outcomes of BLVR with endobronchial valves in patients with $\mathrm{FEV}_{1} \leq 20 \%$ predicted. Patients' $\mathrm{FEV}_{1}$ and the 6 - minute walking distance after 30 and 90 days improved. The rate of complications was not higher than that reported for emphysema patients with better lung function, i.e., $\mathrm{FEV}_{1}>20 \%$, and treated with BLVR [3].

Patients with very severe COPD suffer from agonizing dyspnea and diminished quality of life [11]. As inhaler medications have been tested almost entirely on moderately affected COPD patients, evidence regarding their efficacy in the group of patients with $\mathrm{FEV}_{1} \leq 20 \%$ predicted is scarce. Patients with COPD GOLD stage IV are underrepresented or excluded in the vast majority of clinical COPD studies. Although lung transplantation might be an option for younger patients, the rate of lung deterioration for emphysema is slower than for other disorders, such as cystic fibrosis and idiopathic pulmonary fibrosis. Therefore, with the new allocation scoring systems, emphysema patients rarely gain priority on lung transplant waiting lists [12]. For this group of patients, a nontransplant therapy that improves exercise capacity and quality of life is urgently needed.

In the NETT trial, the mortality of patients submitted to surgical lung volume reduction was significantly higher for patients with $\mathrm{FEV}_{1} \leq 20 \%$ predicted [1] than for those with higher $\mathrm{FEV}_{1}$. This is the reason why patients with very low predicted $\mathrm{FEV}_{1} \%$ were excluded from early trials of BLVR [13]. Although a lower threshold of FEV $15 \%$ predicted was chosen in the VENT trial, the mean predicted $\mathrm{FEV}_{1}$ of the patients in the study was $30 \%$, indicating that the majority, if not all of the study patients, had a predicted $\mathrm{FEV}_{1}$ above the threshold of $20 \%$. In subsequent controlled trials, only few low-FEV 1 predicted patients ( 3 in BeLieVeR-HIFi and 5 in STELVIO [pers. commun.]) were included $[3,14]$.

Hyperinflation is related to a reduced exercise capacity leading to limited daily activities of the affected patients, a meaningful factor for a decreased quality of life [15-17]. Patients with severe hyperinflation are appropriate candidates for BLVR $[4,14]$. It is known that with increasing severity of the disease and worsening airflow, there is also an increase in hyperinflation $[15,18]$. It can be expected that patients with very severe COPD, as indicated by limited airflow, are patients who will benefit from BLVR therapy. Therefore, the procedure should be offered as an option to this patient population.
Taking into account the decreased lung function and the high levels of comorbidity, safety issues are of paramount importance when treating low-FEV 1 patients. Improved patient selection is the reason for an increasing post-BLVR pneumothorax rate, up to $23 \%$ in recent years [19]. The pneumothorax rate after BLVR found in our study (i.e., 20\%) is comparable to the rate described in the literature [20]. Developing a pneumothorax after BLVR is considered as a predictor of clinical success in the long term. A mean target lobe volume reduction of $65 \%$ was observed to lead to improvements in terms of lung function and quality of life in the patients studied by Gompelmann et al. [20]. However, patients are at risk for periprocedural pneumothorax, sometimes tension pneumothorax, leading to a highly acute emergency situation, particularly in the first $72 \mathrm{~h}$ after BLVR [20]. When this occurs, immediate placement of a chest tube is necessary to prevent respiratory failure. In our institution, patients are supervised for $24 \mathrm{~h}$ in the ICU and are not discharged before the fourth day after BLVR. In 4 patients of the present cohort, chest tube placement could be performed immediately because of the close 24 -h supervision in the ICU. We, therefore, believe that close supervision, preferably in the ICU for at least $24 \mathrm{~h}$ after the bronchoscopic procedure, provides optimal patient care and improvement in outcome.

Ventilatory insufficiency is frequently present in low$\mathrm{FEV}_{1}$ patients [21]. COPD exacerbation is a known complication after BLVR that might lead to an increased respiratory effort. It is, therefore, important to emphasize that for all patients with ventilatory insufficiency, noninvasive ventilation has to be implemented before valve placement. However, positive-pressure ventilation should be withdrawn immediately after BLVR to prevent tension pneumothorax.

The low-FEV 1 patients treated with BLVR in this study showed improvements in lung function tests and exercise capacity comparable to patients with better pre-BLVR lung function $[3,4]$. Therefore, the clinical improvements derived from BLVR with valves seem to be independent of pretreatment $\mathrm{FEV}_{1}$ level. Consequently, BLVR with endobronchial valves may also be considered in this severely impaired group of patients when collateral ventilation of the target lobe is excluded. When radiologically confirmed lung volume reduction was achieved, patients enjoyed a substantial physiological benefit.

The limitations of this study are the retrospective nature of the analysis, a lack of quality of life data before and after treatment, and also the missing volumetric HRCT scan software, as emphysema quantification might im- 
prove target lobe selection. Because this study cohort is relatively small, further prospective studies including quality of life data and software-based emphysema quantification to confirm efficacy of BLVR in low-FEV 1 patients are needed.

\section{Conclusion}

The results of this study show for the first time that, in the hands of an experienced team, BLVR with valve placement is feasible even in emphysema patients with low $\mathrm{FEV}_{1}$ of $\leq 20 \%$ predicted. This can be achieved without an increase in complication rates when patients are selected by an experienced multidisciplinary team and intensively monitored after the procedure.

\section{Acknowledgments}

The authors wish to thank Lea Pieper, Ulrike Sampel, and Anne Saha (Ruhrlandklinik Essen, Germany) for their assistance in data collection.

\section{Funding Sources}

There were no funding sources.

\section{Financial Disclosure and Conflicts of Interest}

K.D. and L.F. received travel grants and speakers fees from Pulmonx. All other authors reported no potential conflicts of interest with any companies or organizations whose products or services may have been discussed in this article.

\section{References}

-1 Fishman A, Martinez F, Naunheim K, Piantadosi S, Wise R, Ries A, Weinmann G, Wood DE; National Emphysema Treatment Trial Research Group: A randomized trial comparing lung-volume-reduction surgery with medical therapy for severe emphysema. N Engl J Med 2003;348:2059-2073.

2 Sciurba FC, Ernst A, Herth FJ, Strange C, Criner GJ, Marquette CH, Kovitz KL, Chiacchierini RP, Goldin J, McLennan G; VENT Study Research Group: A randomized study of endobronchial valves for advanced emphysema. N Engl J Med 2010;363:1233-1244.

-3 Klooster K, Ten Hacken NH, Hartman JE, Kerstjens HA, van Rikxoort EM, Slebos DJ: Endobronchial valves for emphysema without interlobar collateral ventilation. $\mathrm{N}$ Engl J Med 2015;373:2325-2335.

4 Herth FJ, Eberhardt R, Gompelmann D, Ficker JH, Wagner M, Ek L, Schmidt B, Slebos DJ: Radiological and clinical outcomes of using Chartis ${ }^{\mathrm{TM}}$ to plan endobronchial valve treatment. Eur Respir J 2013;41:302-308.

-5 Vanfleteren LE, Spruit MA, Groenen M, Gaffron S, van Empel VP, Bruijnzeel PL, Rutten EP, Op 't Roodt J, Wouters EF, Franssen FM: Clusters of comorbidities based on validated objective measurements and systemic inflammation in patients with chronic obstructive pulmonary disease. Am J Respir Crit Care Med 2013;187:728-735.

- 6 Herzog D, Thomsen C, Poellinger A, Doellinger F, Schreiter N, Froeling V, Schuermann D, Temmesfeld-Wollbruck B, Hippenstiel S, Suttorp N, Huebner RH: Outcomes of endobronchial valve treatment based on the precise criteria of an endobronchial catheter for detection of collateral ventilation under spontaneous breathing. Respiration 2016;91:69-78.

-7 Freitag L, Lenkens D, Zarogoulidis P, KarpfWissel R, Hang H, Darwiche K: Functional bronchoscopy: development of a new bronchoscopic method for real-time gas exchange assessment of lobes and lung segments. Respiration 2014;88:469-477.

-8 Donohue JF: Minimal clinically important differences in COPD lung function. COPD 2005;2:111-124.

-9 Puhan MA, Chandra D, Mosenifar Z, Ries A, Make B, Hansel NN, Wise RA, Sciurba F; National Emphysema Treatment Trial (NETT) Research Group: The minimal important difference of exercise tests in severe COPD. Eur Respir J 2011;37:784-790.

10 Hartman JE, Ten Hacken NH, Klooster K, Boezen HM, de Greef MH, Slebos DJ: The minimal important difference for residual volume in patients with severe emphysema. Eur Respir J 2012;40:1137-1141.

11 Gore JM, Brophy CJ, Greenstone MA: How well do we care for patients with end stage chronic obstructive pulmonary disease (COPD)? A comparison of palliative care and quality of life in COPD and lung cancer. Tho$\operatorname{rax} 2000 ; 55: 1000-1006$.

12 Venuta F, Diso D, Anile M, De Giacomo T, Rendina EA, Rolla M, Ricella C, Coloni GF: Bronchoscopic lung volume reduction as a bridge to lung transplantation in patients with chronic obstructive pulmonary disease. Eur J Cardiothorac Surg 2011;39:364-367.

13 Wan IY, Toma TP, Geddes DM, Snell G, Williams T, Venuta F, Yim AP: Bronchoscopic lung volume reduction for end-stage emphysema: report on the first 98 patients. Chest 2006;129:518-526.

14 Davey C, Zoumot Z, Jordan S, McNulty WH, Carr DH, Hind MD, Hansell DM, Rubens MB, Banya W, Polkey MI, Shah PL, Hopkinson NS: Bronchoscopic lung volume reduction with endobronchial valves for patients with heterogeneous emphysema and intact interlobar fissures (the BeLieVeR-HIFi study): a randomised controlled trial. Lancet 2015;386:1066-1073.

15 Gagnon P, Guenette JA, Langer D, Laviolette L, Mainguy V, Maltais F, Ribeiro F, Saey D: Pathogenesis of hyperinflation in chronic obstructive pulmonary disease. Int J Chron Obstruct Pulmon Dis 2014;9:187-201.

16 Garcia-Rio F, Lores V, Mediano O, Rojo B, Hernanz A, López-Collazo E, Alvarez-Sala R: Daily physical activity in patients with chronic obstructive pulmonary disease is mainly associated with dynamic hyperinflation. Am J Respir Crit Care Med 2009;180:506-512.

17 Jones PW: Activity limitation and quality of life in COPD. COPD 2007;4:273-278.

18 Deesomchok A, Webb KA, Forkert L, Lam YM, Ofir D, Jensen D, O’Donnell DE: Lung hyperinflation and its reversibility in patients with airway obstruction of varying severity. COPD 2010;7:428-437.

19 Gompelmann D, Eberhardt R, Herth FJ: Novel endoscopic approaches to treating chronic obstructive pulmonary disease and emphysema. Semin Respir Crit Care Med 2015;36: 609-615.

20 Gompelmann D, Herth FJ, Slebos DJ, Valipour A, Ernst A, Criner GJ, Eberhardt R: Pneumothorax following endobronchial valve therapy and its impact on clinical outcomes in severe emphysema. Respiration 2014;87:485-491.

21 Köhnlein T, Windisch W, Köhler D, Drabik A, Geiseler J, Hartl S, Karg O, LaierGroeneveld G, Nava S, Schönhofer B, Schucher B, Wegscheider K, Criée CP, Welte T: Non-invasive positive pressure ventilation for the treatment of severe stable chronic obstructive pulmonary disease: a prospective, multicentre, randomised, controlled clinical trial. Lancet Respir Med 2014;2:698-705. 